\title{
Preliminary studies on the zoonotic importance of rodents as a reservoir of toxocariasis from recreation grounds in Wroclaw (Poland)
}

\author{
J. HILDEBRAND, G. ZALESNY, A. OKULEWICZ, K. BASZKIEWICZ
}

\begin{abstract}
Department of Parasitology, Institute of Genetics and Microbiology, University of Wroclaw, Przybyszewskiego 63, 51-148 Wroclaw, E-mail: hild@microb.uni.wroc.pl
\end{abstract}

\begin{abstract}
Summary
Due to their specific biology and behaviour, rodents could play a role as an intermediate, definitive or paratenic host for many helminth species, as well as for species of zoonotic significance such as Toxocara spp. or Echinococcus multilocularis. The aim of our preliminary study was to investigate the nematode fauna of rodents collected from recreation grounds located in the vicinity of Wroclaw, and to determine their role in the transmission of toxocariasis in this area. During a one-year period, 90 individuals belonging to three rodent species, i.e. Apodemus agrarius, $A$. flavicollis and Myodes glareolus, were collected. The overall prevalence of infection with nematodes amounted to $63.33 \pm 10.15 \%$ and differed between hosts. Toxocara spp. larvae were located in livers and brains of $A$. agrarius $(12.9 \%)$. Our results indicate a role of rodents in the circulation of toxocariasis in sub-urban areas, which serve as recreation grounds for the city of Wroclaw.
\end{abstract}

Keywords: nematodes; Toxocara; rodents

\section{Introduction}

Rodents could play a role as an intermediate, definitive or paratenic host for many helminth species on account of their specific biology and behaviour. According to Pojmanska et al. (2007), 15 species of digenean trematodes, 30 species of cestodes and 40 species of nematodes were reported in small rodents across Poland. In the helminth fauna of rodents we can find species of zoonotic significance such as Toxocara spp. or Echinococcus multilocularis that use small mammals as paratenic hosts. Toxocariasis is a serious zoonosis reported in humans, in which case the main sources of infection are domestic animals (e.g. dogs and cats). Simultaneously, Toxocara spp. is also detected in wild carnivores (e.g. foxes). The recent growth in the size of the fox population and their synanthropization has increased the risk of transmission of Toxocara spp. between urban and sylvatic cycles. This phenomenon is especially associated with suburban and rural areas (Antolova et al., 2004) as they could function as recreation grounds. Rodents can transmit the infectious agents to pets or domestic animals, which could faciliate the further transmission to humans. They can also play an important role as reservoir hosts for vector-borne diseases such as babesiosis, borreliosis or bartonellosis. In recent years, issues concerning the role of small mammals as the aetiological factor of parasitic zoonosis have been discussed widely (Dubinský et al., 1995; Eckert \& Deplazes, 2004; Deplazes et al., 2004; Pawelczyk et al., 2004; Antolová et al., 2005; Welc-Falęciak et al., 2008). The growth of interest in epizootiological studies on micromammals has contributed to the development of methods used in diagnosis of zoonotical agents within this group of hosts. It was also observed in the instance of methods applying to recovery of Toxocara spp. in paratenic hosts both experimentally (Prokopic \& Figallova, 1982; Lescano et al., 2004; Borecka et al., 2008) and in field studies (Dubinský et al., 1995; Antolová et al., 2005).

The aims of our study were investigations of the nematode fauna of rodents collected from recreation grounds located in the environs of Wroclaw and an attempt to determine the role of rodents in the transmission of Toxocara spp. in this area.

\section{Materials and methods}

Study area and sampling of hosts

In our preliminary studies, rodents were trapped in the Redzin forest ( $\left.51^{\circ} 10^{\prime} 19^{\prime \prime} \mathrm{N} / 16^{\circ} 57^{\prime} 02^{\prime \prime}\right)$, which functions as a recreation ground for the inhabitants of Wroclaw. The forest is located in the north-western part of the city. It is one of the biggest wooded areas within Wroclaw, distinguished by rich flora and fauna including many carnivorous species (e.g. foxes, martens and badgers). 
Table 1. The structure of collected rodents

\begin{tabular}{lccc}
\hline & males & females & total \\
\hline A. agrarius & 10 & 21 & 31 \\
A. flavicollis & 14 & 22 & 36 \\
M. glareolus & 11 & 12 & 23 \\
Total & 35 & 55 & 90 \\
\hline
\end{tabular}

Wooden traps were placed in the afternoon and collected early in the morning on the next day. Collection of rodents was conducted during a one-year period in 2007. In the laboratory, after anesthesia, mice were killed by cervical dislocation, and their alimentary canals and organs were subjected to parasitological examination. In order to find Toxocara spp. larvae, brains and livers were studied under a light microscope by the compression method (Prokopic \& Figallova, 1982). Organs were cut into small pieces and squeezed between glass plates and examined for presence of larval stages. Although during our parasitological examination helminths representing Digenea, Cestoda and Nematoda were collected, this study was limited to the nematode parasites only. The material obtained was maintained in $70 \%$ ethanol, fixed and cleared for examination with glycerol, and identified using available literature data.

\section{Ecological analysis}

The use of descriptive ecological terms follows Bush et al. (1997). The total number of nematode species and prevalence of infection (with $95 \%$ confidence intervals) for particular host species were calculated. According to
Behnke et al. (2008) the infracommunity structure was assessed by the mean (with standard error of the mean S.E.M) and maximum number of nematode species per host, the mean (with S.E.M) number of nematode individuals, and the mean abundance and prevalence of particular species. The differences between prevalence of infection within particular host species were tested by the chi-square test. In order to estimate the degree of parasite aggregation, the index of discrepancy $(D)$ (Poulin, 1993) was calculated using Quantitative Parasitology 3.0 implemented by Rozsa et al. (2000).

\section{Results}

In our preliminary studies 90 individuals belonging to three species, i.e. Apodemus agrarius, A. flavicollis and Myodes glareolus, were collected. The sex and number of trapped rodents are given in Table 1. The overall prevalence of infection with nematodes amounted to $63.33 \pm$ $10.15 \%$ and differed between species of hosts $\left(\chi^{2}=\right.$ 19.133 , df $=2, \mathrm{p}<0.000)$. The highest prevalence was observed in $A$. agrarius $(93.5 \% \pm 5.7)$, the lowest in $M$. glareolus $(39.1 \% \pm 22.3)$ while the level of infection of $A$. flavicollis equaled $55.6 \% \pm 16.5$. We described the component community structure of nematodes for particular host species by prevalence, mean/median intensity and index of discrepancy; the data are summarized in Table 2. Rodents belonging to the genus Apodemus harboured four (A. agrarius) and five (A. flavicollis) nematode species while $M$. glareolus was infected only with $H$. mixtum and A. annulosa. Accurate data on the infracommunity structure are given in Table 3.

Table 2. The prevalence, mean and median intensity of helminths by host

\begin{tabular}{|c|c|c|c|c|c|c|}
\hline \multirow{2}{*}{ Species } & \multicolumn{2}{|c|}{ No. of hosts } & \multirow{2}{*}{$\begin{array}{c}\text { Prevalence } \pm \\
95 \% \\
\text { confidence } \\
\text { limit } \\
\end{array}$} & \multicolumn{2}{|c|}{ Intensity } & \multirow{2}{*}{$\begin{array}{c}\text { Index of } \\
\text { discrepancy }\end{array}$} \\
\hline & Total & Infected & & Mean & Median & \\
\hline \multicolumn{7}{|c|}{ Apodemus agrarius } \\
\hline $\begin{array}{l}\text { Heligmosomoides } \\
\text { polygyrus }\end{array}$ & 31 & 27 & $87.1 \pm 12.6$ & 17.41 & 10.00 & 0.546 \\
\hline $\begin{array}{l}\text { Syphacia } \\
\text { agraria }\end{array}$ & 31 & 3 & $9.7 \pm 11.8$ & 42.33 & 18.0 & 0.918 \\
\hline Heterakis spumosa & 31 & 26 & $83.9 \pm 14.1$ & 34.77 & 22.5 & 0.556 \\
\hline Toxocara spp. & 31 & 4 & $12.9 \pm 13.1$ & 2.25 & 1.00 & 0.896 \\
\hline Overall & 31 & 29 & $93.5 \pm 9.85$ & 52.07 & 38.0 & 0.493 \\
\hline \multicolumn{7}{|c|}{ Apodemus flavicollis } \\
\hline $\begin{array}{l}\text { Heligmosomoides } \\
\text { polygyrus }\end{array}$ & 36 & 16 & $44.4 \pm 16.9$ & 10.30 & 5.5 & 0.760 \\
\hline Syphacia frederici & 36 & 1 & 2.8 & 3.00 & 3.00 & \\
\hline Heterakis spumosa & 36 & 7 & $19.4 \pm 13.9$ & 2.14 & 1.00 & 0.859 \\
\hline Aonchotheca annulosa & 36 & 4 & $11.1 \pm 11.3$ & 7.75 & 8.50 & 0.892 \\
\hline Angiostrongylus sp. & 36 & 1 & 2.8 & 4.00 & 4.00 & \\
\hline Overall & 36 & 20 & $55.6 \pm 17.0$ & 11.00 & 3.50 & 0.737 \\
\hline \multicolumn{7}{|c|}{ Myodes glareolus } \\
\hline Heligmosomum mixtum & 23 & 9 & $39.1 \pm 20.8$ & 1.44 & 1.0 & 0.686 \\
\hline Aonchotheca annulosa & 23 & 2 & $8.7 \pm 11.3$ & 8.50 & 8.50 & 0.892 \\
\hline Overall & 23 & 9 & $39.1 \pm 20.8$ & 3.33 & 1.0 & 0.792 \\
\hline
\end{tabular}


Table 3. Measures of infracommunity structure by host

\begin{tabular}{lccc}
\hline & \multicolumn{3}{c}{ Host } \\
\cline { 2 - 4 } & A. agrarius & A.flavicollis & M. glareolus \\
Maximum number of nematode species per host & 3 & 3 & 2 \\
Mean number of nematode species \pm S.E.M & $1.81 \pm 0.12$ & $0.88 \pm 0.16$ & $0.48 \pm 0.14$ \\
Mean number of nematodes \pm S.E.M & $48.71 \pm 9.09$ & $6.11 \pm 1.77$ & $1.30 \pm 0.68$ \\
\hline
\end{tabular}

During microscopic examination of livers and brains Toxocara spp. larvae were reported only for A. agrarius (Fig. 1). Larvae were found in four individuals; in three cases larvae were located in the liver and once in the brain. Intensity ranged between 3 to 6 specimens per host; the prevalence and mean intensity are given in Table 2 .

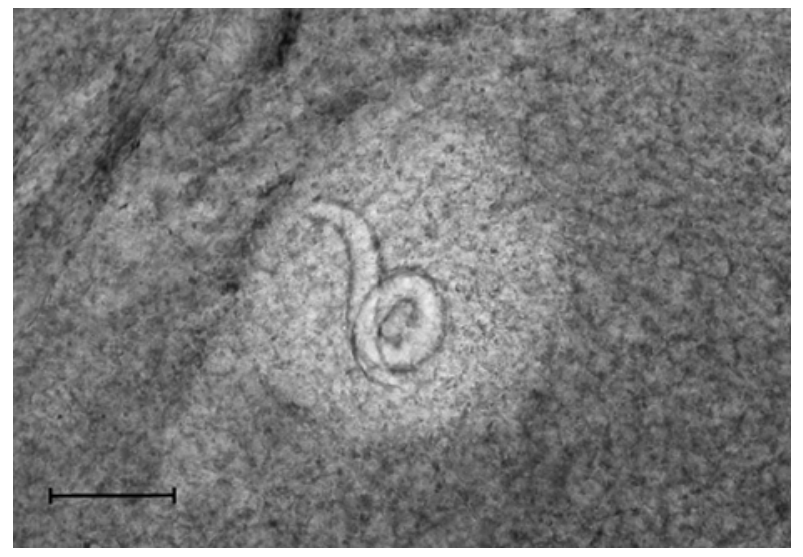

Fig. 1. Toxocara spp. larva in the liver $($ scale bar $=100 \mu \mathrm{m})$

\section{Discussion}

Numerous studies on the parasite fauna of rodents concerning various aspects, such as the impact of extrinsic and intrinsic factors on helminth interactions, have been carried out in recent years (Bajer et al., 2005; Behnke et al., 2005; Eira et al., 2006; Fuentes et al., 2007). Apart from ecological aspects, relevant information about the taxonomical status or host-parasite relationship became apparent during investigations on the helminth fauna of rodents (Feliu et al., 2000; Hildebrand et al., 2004; Hildebrand et al., 2007a). Moreover, recent studies show that the possible parasite spectrum has not yet been completely described (Haukisalmi \& Henttonen, 2001, 2005; Hildebrand et al., 2007b).

The number of nematode species reported in murid or arvicolid rodents is inconstant, differing between sites and depending on climatic changes (Abu-Madi et al., 2000; Bajer et al., 2005; Behnke et al., 2008). According to Pojmanska (1998), the nematode fauna of M. glareolus in Poland is represented by 13 species, though some statements are still debatable (Tenora \& Meszaros, 1975; Hildebrand et al., 2007a). In our study, only two species, H. mixtum and A. annulosa, were found. It is a rather poor result compared with other research carried out in Poland or Europe. During their long-term studies on the helminth structure of bank voles in the Mazury Lake District, Bajer et al. (2005) recorded five nematode species. Similar nematode species richness was also reported by Hauki- salmi et al. (1988). In comparison with these cyclic and long-term investigations, our results take on a preliminary character.

Most papers describing the parasite fauna of rodents representing the genus Apodemus pertain to A. sylvaticus (Behnke et al., 1999; Abu-Madi et al., 2000; Fuentes et al., 2007). So far only a study from Germany (Klimpel et al., 2007) refers to the parasites of $A$. flavicollis. Our results indicate the presence of five nematode species harbouring A. flavicollis. The same number of species was observed by Klimpel et al. (2007). The remarkable similarities observed in the nematode fauna of these mouse species can be associated with their similar pattern of living (Klimpel et al., 2007). The only difference in the nematode community of rodents from the Redzin forest is the high prevalence of $H$. spumosa. This species has been reported mainly from $A$. agrarius or Rattus sp. and its presence in the field mouse species (A. flavicollis and A. sylvaticus) seems occasional (Klimpel et al., 2007). During our parasitological examination of $A$. flavicollis, nematodes belonging to the genus Angiostrongylus were detected but the prevalence was low as compared with data presented by Eira et al. (2006) and Gouy de Bellocq et al. (2003).

Another species of the genus Apodemus, i.e. A. agrarius, does not constitute a frequent subject of parasitological investigations. During long-term studies on the helminth fauna of the striped field mouse in the Belorussian Polesie region, Shimalov (2002) reported six nematode species. In our preliminary study, four species were reported and $A$. agrarius was the most frequently infected host species; the prevalence and mean number of nematode species were two times higher than in A. flavicollis. Besides the typical species such as $H$. polygyrus, $H$. spumosa and $S$. agraria, we found larvae of Toxocara spp. located in the brains and livers. Research on the zoonotic importance of rodents in the circulation of Toxocara spp. has been pursued only in Slovakia (Dubinský et al., 1995 and Antolová et al., 2004). The most frequent seropositive species was $A$. agrarius $(15.9 \%)$ and the seropositivity of small mammals was higher at sub-urban localities (Antolová et al., 2004). In our study the prevalence reached $12.9 \%$ and was reported only for $A$. agrarius. Small mammals as paratenic hosts are a significant reservoir of Toxocara larvae. These results may suggest the risk of the transmission of pathogens into red foxes as main disseminators of Toxocara spp. eggs in sub-urban areas, which contitute recreation grounds for Wroclaw inhabitants.

\section{References}

Abu-Madi, M. A., BehnKe, J. M., Lewis, J. W., Gilbert, 
F. S. (2000): Seasonal and site specific variation in the component community structure of intestinal helminths in Apodemus sylvaticus from three contrasting habitats in South-East England. J. Helminth., 74: 7 - 15

Antolová, D., Reiterová, K., Miterpaková, M., STANKO, M., DUBINSKÝ, P. (2004): Circulation of Toxoca$r a$ spp. in suburban and rural ecosystems in the Slovak Republic. Vet. Parasit., 126, 317 - 324

Bajer, A., Behnke, J. M., PawelczyK, A., Kulis, K., SEREDA, M. J., SinsKi, E. (2005): Medium-term temporal stability of the helminth component community structure in bank voles (Clethrionomys glareolus) from the Mazury Lake District region of Poland. Parasitology, 130: 213 228

BehnKe, J. M., Lewis, J. W., Mohd Zain, S. N., Gilbert, F. S. (1999): Helminth infections in Apodemus sylvaticus in southern England: interactive effects of host age, sex and year on the prevalence and abundance of infections. $J$. Helminth., 73: $31-44$

BehnKe, J. M, Gilbert, F. S., AbU-Madi, M. A., Lewis, J. W. (2005): Do the helminth parasites of wood mice interact? J. Anim. Ecol., 74: 982 - 993

BehnKe, J. M., BAJER, A., HARris, P. D., Newington, L., Pidgeon, E., Rowlands, G., Sheriff, C., KulisMalkowska, K., Sinski, E., Gilbert, F. S., Barnard, C. J. (2008): Temporal and between-site variation in helminth communities of bank voles (Myodes glareolus) from N.E. Poland. 2. The infracommunity level. Parasitology, 135: $999-1018$

Borecka, A., Gawor, J., Niedworok, M., Sordyl, B. (2008): Detection of Toxocara canis larvae by PCR in the liver of experimentally infected Mongolian gerbils ( $\mathrm{Me}$ riones unguiculatus). Helminthologia, 45: 147 - 149

Bush, A. O., Lafferty, K. D., Lotz, J. M., Shostak, A. W. (1997): Parasitology meets ecology on its own terms: Margolis et al. revisited. J. Parasit., 83: 575 - 583

Deplazes, P., Hegglin, D., Gloor, S., Roming, T. (2004): Wilderness in the city: the urbanization of Echinococcus multilocularis. Trends Parasitol., 20: $77-84$

Dubinský, P., Havasiová-Reiterová, K., PeŤKo, B., HovorkA, I., TOMAŠOviČOVÁ, O. (1995): Role of small mammals in the epidemiology of toxocariasis. Parasitology, 110: $187-93$

ECKerT, J., DePlazes, P. (2004): Biological, epidemiological, and clinical aspects of echinococcosis, a zoonosis of increasing concern. Clin. Microbiol. Rev., 17: 107 - 35

Eira, C., Torres, J., Vingada, J., Miquel, J. (2006): Ecological aspects influencing the helminth community of the wood mouse Apodemus sylvaticus in Dunas de Mira, Portugal. Acta Parasit., 51: 300 - 308

Feliu, C., Špakulová, M., Casanova, J. C., Renaud, F., Morand, S., Hugot J. P., Santalla, F., Durand, P. (2000): Genetic and morphological heterogeneity in small rodent whipworms in southwestern Europe: characterization of Trichuris muris and description of Trichuris arvicolae n. sp. (Nematoda: Trichuridae). J. Parasit., 86: 442 449

Fuentes, M. V., Sainz-Elipe, S., Galan-Puchades, M.
T. (2007): Ecological study of the wood mouse helminth community in a burned Mediterranean ecosystem in regneration five years after a wildfire. Acta Parasit., 52: 403 413

Gouy de Bellocq, J., Sara, M., Casanova, J.C., Feliu, J., MORAND, S. (2003): A comparison of the structure of helminth communities in the woodmouse, Apodemus sylvaticus, on islands of the western Mediterranean and continental Europe. Parasitol. Res., 90: $60-70$

HaUkisalmi, V., HentTonen, H. (2001): Biogeography of helminth parasitism in Lemmus link (Arvicolinae), with the description of Paranoplocephala fellmani n. sp. (Cestoda: Anoplocephalidae) from the Norwegian lemming L. lemmus (Linnaeus). Sys. Parasit., 49: 7 - 22

Haukisalmi, V., Henttonen, H. (2005): Description of Paranoplocephala yoccozi n. sp. (Cestoda: Anoplocephalidae) from the snow vole Chionomys nivalis in France, with a review of anoplocephalid cestodes of snow voles in Europe. Parasite, 13: $203-211$

Haukisalmi, V., Henttonen, H., Tenora, F. (1988): Population dynamics of common and rare helminths in cyclic vole populations. J. Anim. Ecol., 57: 807 - 825

Hildebrand, J., Popiolek, M., OKulewicz A., Zalesny, G. (2004): Helminth fauna of rodents from genus Apodemus from Wroclaw area. Wiad. Parazyt., 50: 623 - 628 [in Polish]

Hildebrand, J., Zalesny, G., OKulewicz, A. (2007a): A new whipworm from arvicolid rodents, Trichuris arvicolae Feliu et al. 2000, in the helminth fauna of Poland. Wiad. Parazyt., 53: 339 - 341

Hildebrand, J., OKulewicz, J., Popiolek, M. (2007b): A new dicrocoeliid from the bank vole Clethrionomys glareolus (Rodentia: Microtidae) from Poland. J. Parasit., 93: $151-154$

KLIMPEL, S., Forster, M., SchMAhl, G. (2007): Parasites of two abundand sympatric rodent species in relation to host phylogeny and ecology. Parasitol. Res., 100: 867-875 Lescano, S. Z., Querioz, M. L., ChiefFi, P. P. (2004): Larval recovery of Toxocara canis in organs and tissues of experimentally infected Rattus norvegicus. Mem. Inst. Oswaldo Cruz. 99: 627 - 628

PawelczyK, A., Bajer, A., BehnKe, J. M., Gilbert, F. S., SINSKI, E. (2004): Factors affecting the component community structure of haemoparasites in common voles (Microtus arvalis) from the Mazury Lake District region of Poland. Parasitol. Res., 92: 270 - 284

PojMANSKA, T. (1998): Catalog of Polish parasitological fauna. Part V. Parasites of mammals. Insectivora, Chiroptera, Lagomorpha, Rodentia: endoparasites. pp. 202, Polish Parasitological Society, Warsaw, Poland. [in Polish] Pojmanska, T., Niewadomska, K., OKulewicz, A. (2007): Parasitic helminths of Poland. Species, hosts, blank pages. pp. 360, Polish Parasitological Society, Warsaw, Poland. [in Polish]

Poulin, R. (1993): The disparity between observed and uniform distributions: A new look at parasite aggregation. Int. J. Parasit., 23: 937 - 944

Prokopic, J., Figallova, V. (1982): The migration of 
larvae of Toxascaris leonina (Linstow, 1909) in experimentally infected white mice. Folia Parasitol. 29: 233 238

RozsA, L., Reiczigel, J., MAJoros, G. (2000): Quantifying parasites in samples of hosts. J. Parasit., 86: 228 - 232

ShimaloV, V. V. (2002): Helminth fauna of the stripped field mouse (Apodemus agrarius Pallas, 1778) in ecosystems of Belorussian Polesie transformed as a result of reclamation. Parasitol. Res., 88: 1009 - 1010

RECEIVED August 20, 2008
Tenora, F., Meszaros, F. (1975): Nematodes of the genus Syphacia Seurat, 1916 (Nematoda) - parasites of rodents (Rodentia) in Czechoslovakia and Hungary. Acta Univ. Agric., 3: 537 - 554

Welc-Falęciak, R., PAZIEWska, A., Bajer, A., BehnKe, J.M., SINSKI, E. (2008): Bartonella spp. infection in rodents from different habitats in the Lake Mazury District, Northeast Poland. Vector Borne Zoonotic Dis., 8: 467 474

ACCEPTED FEBRUARY 16, 2009 